\title{
Estimating Fuelwood Demand and Supply for Forest User Groups from Community Forests
}

\author{
Suman Aryal ${ }^{1}$, Govinda Raj Pokharel ${ }^{2}$, Narayan Prasad Kafle ${ }^{2}$ \\ and Narayan Prasad Gaire ${ }^{1}$ \\ ${ }^{I}$ Central Department of Environmental Science, Tribhuvan University, Kathmandu, Nepal \\ ${ }^{2}$ Alternative Energy Promotion Centre, Khumaltar, Lalitpur, Nepal \\ e-mail: aaryalsuman@gmail.com
}

\begin{abstract}
Main objectives of this study were to estimate annual fuelwood demand in Community Forest Users Group (CFUG), and annual sustainable supply of the same from Community Forest (CF). Study was done each one community forest of Terai and Hills; Shanti Community Forest (SCF), Saljhandi, Rupandehi (Terai) and Barangdikol Community Forest (BCF), Madanpokhara, Palpa (Hill), in Western Development region, Nepal. Extensive field work was carried out from May to July, 2007. Sustainable supply of fuelwood from the CF was estimated by using the methodology mentioned in the "Revised guidelines for community forest resource inventory", MoFSC, 2004. Stratified random sampling with proportional allocation method in three households (HHs) type; HHs with biogas, HHs with ICS and HHs without biogas \& ICS, was used to cover $15 \%$ of the HHs in the CFUG during HHs survey for the estimation of fuelwood demand. The fuelwood consumption pattern in these three HHs types was compared. The result showed that SCF was found in good condition where as BCF was in poor condition based on regeneration rate and growing stock. Demand and supply analysis showed that only $12.03 \%$ of fuelwood demand in SCFUG and $8.03 \%$ of the fuelwood demand in the BCFUG was fulfilled by the sustainable supply of fuelwood from the CF.
\end{abstract}

Key-words: biogas, consumption, energy, improved cooking stove, growing stock

\section{Introduction}

Implementing community forestry in last 30 years, Nepal is pioneer in the Asia Pacific region, and has made a tremendous progress in this sector. Community Forest $(\mathrm{CF})$ is a part of the national forest which is handed over to a Community Forest Users Group (CFUG) for development, protection, management and utilization forest and its products as approved Operation Plan (OP) (Forest Act 1993). One of the very important objectives of $\mathrm{CF}$ is to meet the people's basic need of fuelwood, fodder, timber and other forest products (MoFSC 1988).

Nepal's per capita energy consumption is one of the lowest in the world as well as in the South Asia (IBRD/ WB 2004). About $87.71 \%$ of energy requirement is fulfilled by traditional resources like fuelwood, agricultural residue and animal dung in the year 2005 (WECS 2006). Fuelwood is primary and very important energy resources in Nepal. The actual demand and supply situation of fuelwood is difficult to quantify (Shrestha 1999). But, the quantitative estimation of sustainable yield of fuelwood from the CF, demand of fuelwood in the CFUG give the clear picture of the current consumption pattern and future planning of the $\mathrm{CF}$ for its better management. It also helps to predict the impact of current withdrawal of fuelwood from the forest.

The objectives of this study were to estimate the sustainable supply of fuelwood from the CF, demand of fuelwood in the respective CFUG. Comparison of this situation was made between CF of Terai and Hilly regions. In the course of estimating fuel demand of the CFUG, comparison of fuelwood consumption pattern in different households (HHs) type; HHs with 
biogas, HHs with ICS and HHs without biogas and ICS was made.

\section{Materials and methods}

\section{Site description}

Shanti Community Forest (SCF) with an area of 73 ha $\left(83^{\circ} 15^{\prime} \mathrm{E}\right.$ to $83^{\circ} 17^{\prime} \mathrm{E}$ and $27^{\circ} 40^{\prime} \mathrm{N}$ to $\left.27^{\circ} 42^{\prime} \mathrm{N}\right)$ in Saljhandi Village Development Committee (VDC) of Rupandehi district and Barangdikol Community forest (BCF) with an area of 8.94 ha $\left(83^{\circ} 34^{\prime} \mathrm{E}\right.$ to $83^{\circ} 35^{\prime} \mathrm{E}$ and $27^{\circ} 49^{\prime} \mathrm{N}$ to $27^{\circ} 50^{\prime} \mathrm{N}$ ) in the Madanpokhara VDC of Palpa district were selected for the study. The SCF has four blocks and $\mathrm{BCF}$ has five blocks.

Since SCF lies in Terai, its topography is plain. The altitude ranges from $125 \mathrm{~m}$ to $150 \mathrm{~m}$ asl and climate is of sub-tropical nature. The temperature and rainfall data (1987-2005) obtained from DHM for Taulihawa station (nearest to SCF) were analyzed. The average annual rainfall is $1328.93 \mathrm{~mm}$. The hottest month is May with maximum temperature of $37.48^{\circ} \mathrm{C}$ and minimum temperature of $23.36^{\circ} \mathrm{C}$. The coldest month is January with maximum temperature $21.66^{\circ} \mathrm{C}$ and minimum of $8.51^{\circ} \mathrm{C}$. The dominant tree species in SCF are Shorea robusta and Terminilia alata. Common wild animals in the area are Nilgai, deer, wild boar, rat, rabbit, squirrel, and monkeys. The population of the SCFUG was 2794 and average HHs size was 6 (SCF 2064 BS).

The BCF lies in the hilly region. Its altitude ranges from $690-750 \mathrm{~m}$ asl. The climate is warm temperate. The temperature and rainfall data (19872005) obtained from DHM for Tansen station (nearest to BCF) were analyzed. The average annual rainfall is $1630.702 \mathrm{~mm}$. The hottest month is May with maximum temperature of $29.62^{\circ} \mathrm{C}$ and minimum temperature of $18.74^{\circ} \mathrm{C}$ and the coldest month is January with maximum temperature of $18.55^{\circ} \mathrm{C}$ and minimum of $7.53^{\circ} \mathrm{C}$. The forest is dominated by Castanopsis indica and Schima wallichi. Leopard, monkey, rabbit, porcupine and squirrel were found in the forest. The population in BCFUG was 376 and average HHs size was 5.5 (BCF 2061 BS).

\section{Method of data collection and analysis}

The field work was done from May to July, 2007. The supply of fuelwood from CF was estimated using the methodology of MoFSC (2004). According to this method, the fuelwood can be harvested from CF which consists of two parts. First, fuelwood that can be harvested based on annual yield of the forest and second, fuelwood that can be obtained from forest management activities. First one requires detailed inventory of C.F. Hence, forest inventory of SCF and $\mathrm{BCF}$ was done during field visits. For the second part of fuelwood which is obtained from management activities, the amount of fuelwood value mentioned in the OP was used.

Inventory was made in each block of CF. Sampling intensity was fixed at $0.5 \%$. The distance from first plot to the next was fixed according to the area (ha) of block of the CF and size of the sample plot. Altogether 10 sampling plots of $25 \mathrm{mx} 20 \mathrm{~m}$ were studied for SCF and 10 sampling plots of $20 \mathrm{~m} \times 20 \mathrm{~m}$ were studied for BCF. Procedure of forest inventory followed MoFSC (2004).

Height and diameter at breast height (dbh) of all trees (dbh equal to or more than $10 \mathrm{~cm}$ ) and poles (having dbh from $10 \mathrm{~cm}$ to $30 \mathrm{~cm}$ ) were recorded. The species having dbh less than $10 \mathrm{~cm}$ were counted as regeneration. Sapling (greater than $1 \mathrm{~m}$ height and having dbh less than $10 \mathrm{~cm}$ ) and seedling (height $30 \mathrm{~cm}$ to $1 \mathrm{~m}$ ) were counted in sub-plots of $5 \mathrm{mx} 5 \mathrm{~m}$ and $2 \mathrm{mx} 5 \mathrm{~m}$ respectively inside sampling plot.

Sustainable yield of fuelwood from CF, annual yield of the forest, community forest condition, regeneration condition and growing stock were analyzed using the data as obtained from forest inventory, following MoFSC (2004).

Prior to field survey, structured questionnaire was developed for HHs survey. All the HHs were grouped into three categories: HHs having biogas plant, HHs having improved cooking stoves (ICS) and HHs without biogas plant and ICS. HHs for the interview was selected using stratified random sampling with the proportional allocation method to cover $15 \%$ HHs of the CFUGs. Total numbers of HHs in SCF were 465, out of which $68 \mathrm{HHs}$ were interviewed. Similarly the total numbers of HHs in BCF were 67 out of which $10 \mathrm{HHs}$ were interviewed. Each selected HH was asked about the amount of fuelwood it required for different activities (cooking food, preparation of animal feed, preparation of alcohol) per year. 


\section{Results}

\section{Demand and supply of fuelwood from CF}

Fig. 1 presents the annual demand and supply of fuelwood in SCF and BCF. The total amount of annual harvestable fuelwood was 1, 60, $881 \mathrm{~kg}$ for SCF and 12,
$549.88 \mathrm{~kg}$ for BCF whereas total annual demand of fuelwood was 13,75, 410 kg in SCFUG and 1, 56, $178 \mathrm{~kg}$ in BCFUG (Fig 1). At individual HH level, annual demand of fuelwood was $2957.8 \mathrm{~kg}$ and annual supply from CF was only $345.98 \mathrm{~kg}$ in SCFUG. In BCFUG, demand was $2296.72 \mathrm{~kg}$ and supply of $187.31 \mathrm{Kg}$ at each HHs level.

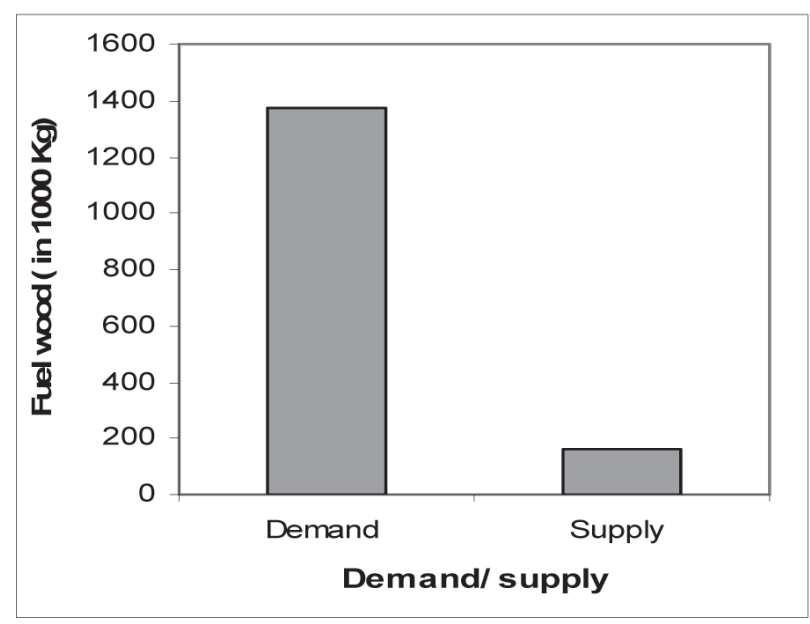

(a)

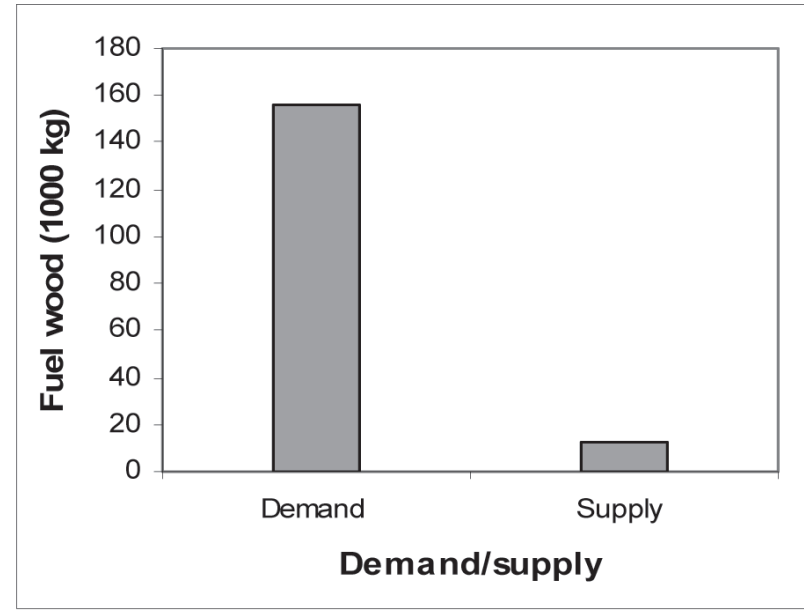

(b)

Fig 1. Annual demand and supply of fuelwood: a) SCF, b) BCF

Table 1 presents the condition of studied community forests based on growing stock (GS) and regeneration rate. Supply of fuelwood from CF depends upon the condition of the forest. In turn, the condition of forest is based on regeneration rate and its growing stock. Based on these two criteria, the SCF was found to be in good condition whereas BCF was in poor condition (MoFSC 2004).

Table 1. Condition of forest based on growing stock (GS) and regeneration rate

\begin{tabular}{l|l|l}
\hline CF & SCF & BCF \\
\hline Sapling/ha & 1,794 & $1,339.59$ \\
Seedling / ha & 2,002 & 869.68 \\
Regeneration condition & Medium & Medium/low \\
Per ha GS $\left(\mathrm{m}^{3}\right)$ & 200.19 & 37.33 \\
Condition of forest & Good & Good \\
\hline
\end{tabular}

\section{Fuelwood consumption pattern in HHs having traditional and ICS}

Fig. 2 presents annual fuelwood consumption pattern in different HHs type at SCFUG and BCFUG. The amount of fuelwood required per year for different HHs type was calculated for both the CFUG for different HHs types. The amount of annual fuelwood required were $2320.46 \mathrm{~kg}, 3755.64$ and $2731.54 \mathrm{~kg}$ for $\mathrm{HHs}$ with biogas,
HHs with ICS and HHs without biogas and ICS respectively in SCFUG. Similarly, the amount of annual fuelwood required were $2093.93 \mathrm{~kg}, 2257.18 \mathrm{~kg}$ and $2545.08 \mathrm{~kg}$ for HHs with biogas, HHs with ICS and HHs without biogas and ICS respectively in BCFUG. On an average, single $\mathrm{HH}$ required $2957.39 \mathrm{~kg} /$ year of fuelwood in SCFG and $2287.65 \mathrm{~g} /$ year in BCFUG (Fig 2). 


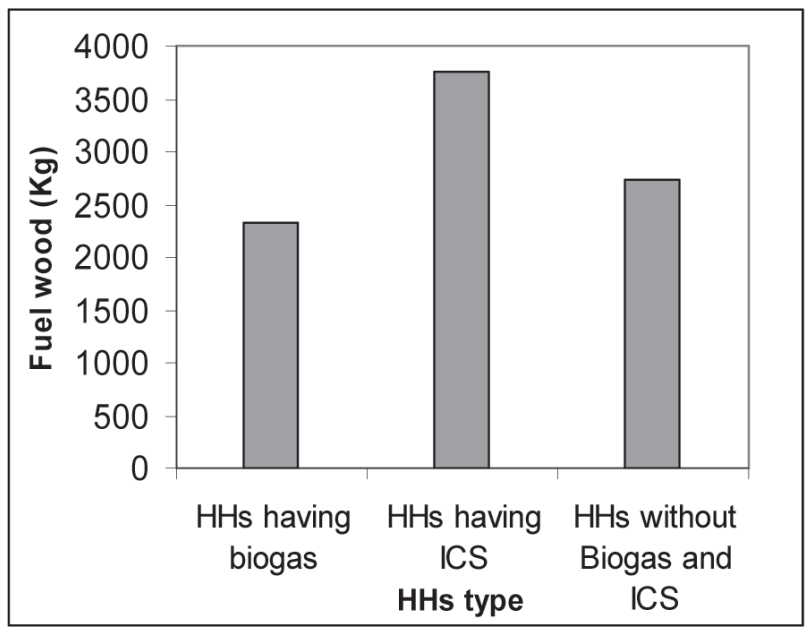

(a)

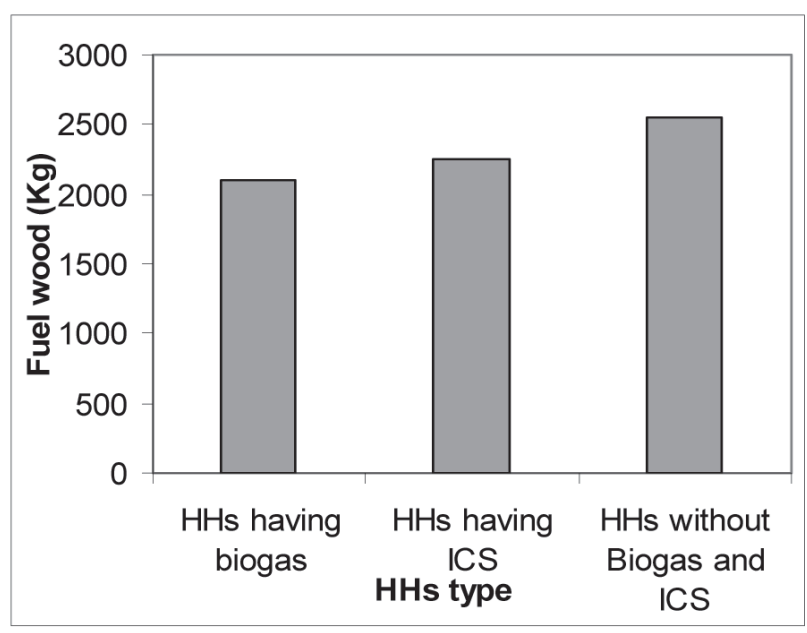

(b)

Fig 2. Annual fuelwood consumption pattern in different HHs types: a) SCFUG, b) BCFUG

\section{Distribution of fuelwood demand for different activities}

Fuelwood was used for different activities like cooking food, preparation of animal feed and preparation of alcohol. The amount of fuelwood consumed for each activity in both the studied CFUGs was calculated.
Fig. 3 presents percentage of total fuelwood required for different activities at SCFUG and BCFUG. About 61.75 $\%$ of fuelwood was used for cooking food in SCFUG. This was $62.31 \%$ in BCFUG. The amount of fuelwood required for preparation of alcohol was nil in BCFUG and about $1 \%$ of fuelwood in SCFUG was used for the preparation of the alcohol (Fig 3).
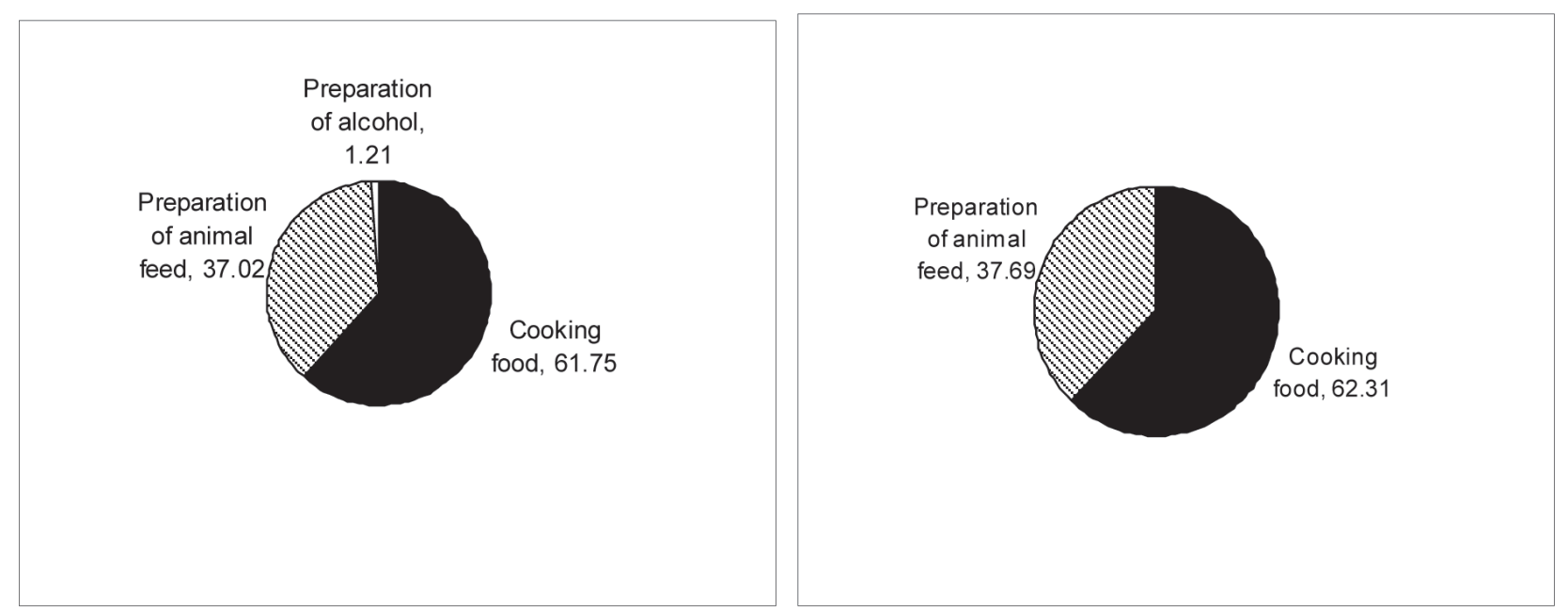

Fig 3. Percentage of total fuelwood required for different activities: a) SCFUG, b) BCFUG

\section{Discussions}

\section{Demand and supply of the fuelwood}

The demand of fuelwood in CFUGs and the supply of fuelwood from the CF showed heavy deficit of fuelwood in both the CFUG. Only $12.03 \%$ of the fuelwood demand in SCFUG and $8.03 \%$ of fuelwood demand in BCFUG was found to be supplied by the sustainable yield from the CF. The determination of the growing stock and regeneration rate of the studied forest showed that the 
SCF was in good condition and BCF was in poor condition. Karki et. al (1994) reported that $32.4 \%$ of required fuelwood was supplied by the users' forest in seven FUGs of Palpa district and Phewa watershed.

Demand and supply factors are very important for the sustainability of the CF. Fuelwood can be sustainably derived from any unit of land only if the rate of growth is equal to or exceeds the rate of extraction. Supply of fuelwood from the forest depends on many factors including availability of per capita forest area in the CFUG, growing stock of the forest, and nature of the species growing in the forest. Demand is directly related to the fuelwood consumption activities and pattern among the CFUGs member. Comparison of supply of fuelwood from $\mathrm{CF}$ at individual $\mathrm{HH}$ showed that it was higher in the SCF. HHs demand of fuelwood was less in BCF than in SCF. This is partly due to HHs size and partly due to installation of fuelwood efficient ICS and biogas.

\section{Fuelwood Consumption pattern in different HHs type}

The quantity of the fuelwood harvest can be reduced by adopting renewable energy technology such as biogas, ICS, bio-briquettes, etc, which ultimately lead to minimize the pressure in the forest. These technologies also help to keep the annual fuelwood harvest within the sustainable annual yield. Comparison of annual wood consumption in different HHs type showed that the fuelwood consumption was lowest in the HHs with biogas installation in both the CFUG. The performance of ICS in reducing fuelwood was found to be satisfactory in the BCFUG. But in case of SCFUG, annual fuelwood consumption in HHs with ICS was higher than the HHs without ICS and Biogas. This result in the SCFUG is incompatible with the other study conducted in the ICS. Interviewers reported that this happened due to faulty design and construction of ICS of large size than required for family size.

The supply of fuelwood from community forest was found to be very low as compared to demand of the forest users. This may be one of the biggest issues for future management of the community forest. HHs with biogas installation is found to consume lowest amount of fuelwood in both the CFUGs. Careful design of ICS according to family size is important to make it efficient and hence reduce fuelwood demand. Faulty design of ICS of large size, which is incompatible with family size, increases the fuelwood demand. Hence, these renewable energy technologies are useful in reducing fuelwood consumption pattern in forest user groups and hence play important role in minimizing the pressure in the forest.

\section{References}

Anonymous. 2007. Climatological records of Nepal 19872005. Department of Hydrology and Meteorology (DHM), Babarhamal, Kathmandu, Nepal.

BCF. 2061 BS. Operatioal plan. Barangdikol Community Forest. Approved from District Forest Office, Palpa, Nepal.

HMG. 1995. The forest act 1993 and the forest regulations 1995. His Majesty's Government: Law Books Management Board, Kathmandu, Nepal

IBRD and World Bank. 2004. World development indicators 2004. International Bank for Reconstruction and Development, Washington DC: World Bank.

Karki, M., J.B.S. Karki, and N. Karki. 1994. Sustainable management of common forest resources: An evaluation of selected forest user groups in western Nepal. International Centre for Integrated Mountain Development, Kathmandu.

MoFSC. 1988. Master plan for forestry sector. Ministry of Forest and Soil Conservation, Kathmandu, Nepal.

MoFSC. 2004. Revised guidelines for community forest resource inventory. Ministry of Forest and Soil Conservation, Community and Private Forest Division, Kathmandu, Nepal.

SCF. 2064 BS. Operatioal plan. Shanti Community Forest. Approved from district forest Office, Rupandehi, Nepal.

Shrestha R. B. 1999. Inadequate supply of fuelwood and timber from forests of Nepal. Banko Jankari 9 (2): 25-27.

WECS. 2006. Energy synopsis report. Water and Energy Commission Secretariat, Kathmandu, Nepal. Report No.7, Sequence No. 489. 
Nepal Journal of Science and Technology 10 (2009) 